\title{
Expansion of the Candida albicans cell envelope in different morphological forms of the fungus
}

\author{
L. A. Merson-Davies ${ }^{1}$ and F. C. Odds ${ }^{2 *}$ \\ ${ }^{1}$ Department of Microbiology, University of Leicester, Leicester LE1 7RH, UK \\ ${ }^{2}$ Department of Bacteriology and Mycology, Janssen Research Foundation, B-2340 Beerse, Belgium
}

(Received 30 August 1991; revised 18 November 1991; accepted 20 November 1991)

\begin{abstract}
Modes of cell envelope expansion were monitored in developing cells of Candida albicans 73/055 to which polystyrene beads were attached. Eight different conditions of culture medium, $\mathrm{pH}$ and temperature were used to promote growth in a variety of morphological forms. The cells were observed microscopically during growth in Sykes-Moore perfusion chambers, and sequential measurements of distances between the bead and the parent cell, and the bead and the apical tip were used to distinguish apical envelope expansion from general envelope expansion. Morphology index (Mi) was determined at each time point as an estimate of each cell's morphology. Calculations based on the measurements showed that general envelope expansion was inversely proportional to Mi, but that general expansion greater than $20 \%$ occurred only in cells with a final $\mathrm{Mi}<\mathbf{2 \cdot 0}$, indicating that regulation of apical and general envelope expansion alone may be insufficient to determine the different morphologies seen in cells with higher Mi. The rate of expansion of the perimeter of cells was linearly proportional to the final Mi. This observation suggests that commitment to morphological development in $C$. albicans may in part involve commitment to a rate of envelope expansion, which itself helps determine the final morphology of a cell.
\end{abstract}

\section{Introduction}

Morphological development in the pleomorphic, pathogenic yeast Candida albicans is determined by the shape of the cell wall (Chattaway et al., 1976). Chitin incorporation in C. albicans walls has been shown to occur primarily at the apex of developing cells, both in buds and in hyphae (Braun \& Calderone, 1978; Elorza et al., 1983) and this observation correlates with the finding that the primary site of cell envelope expansion is the apex in both morphological forms (Staebell \& Soll, 1985).

Indeed, the ingenious study of timings and locations of cell wall expansion by Staebell \& Soll (1985) enormously advanced comprehension of the mechanisms underlying cell shape in C. albicans. The experimentation used by these authors involved attachment of polystyrene beads to the periphery of cell envelope evaginations, and microscopic monitoring of the perimetric distances between bead and apex and between bead and parent

\footnotetext{
*Author for correspondence: Tel. 14 602111; fax 14602841.

Abbreviations: $\mathrm{Mi}$, morphology index; $\mathrm{Mi}_{\mathrm{f}}$, final morphology index (mean of last three Mi determinations during period of active growth); AAS, amino acid/salts medium; YNBG, yeast nitrogen base/glucose medium; MPGB, mycological peptone/glucose broth.
}

cell during subsequent cell expansion. These measurements allowed calculation for each cell of the relative proportions of envelope expansion that occurred in the region of the cell apex and generally throughout the cell envelope.

The study of Staebell \& Soll (1985) showed that expansion in $C$. albicans yeast-cells occurred in two phases: in the first phase of development the envelope expanded primarily in the region of the apex, and in the secondary phase general expansion predominated. In $C$. albicans hyphae, by contrast, apical expansion of the envelope predominated throughout cell development. Thus, the round shapes of yeast cells were accounted for by the phase of general envelope expansion. The absence of such a period of general expansion in hyphae determined their elongated, parallel-sided shape.

The work of Staebell \& Soll (1985) involved environmental conditions that favoured $C$. albicans development either as yeast-cells or true hyphae. Cells with intermediate, pseudohyphal morphologies were not studied, and parameters of envelope expansion in such intermediate forms are unknown. Merson-Davies \& Odds (1989) described a 'morphology index' (Mi) that permits the objective measurement of the shape of a $C$. albicans cell in terms of a dimensionless number (usually in the range 
$0.5-4.5)$ that is a continuous variable. Mi of approximately 1 indicates a spheroidal yeast-cell morphology, while an $\mathrm{Mi}$ of around 4 indicates a parallel-sided, true hyphal morphology. Mi between these extreme values indicates cells with morphologies that are commonly subjectively described as 'pseudohyphae'.

With such an objective measure of the morphological continuum in C. albicans available, the present study was undertaken as an extension of the work of Staebell \& Soll (1985), designed to determine proportions and timings of apical and general cell envelope expansion in cells across the whole range of Mi exhibited by $C$. albicans cells. The cells measured were grown in a variety of culture environments to minimize effects that may be related more specifically to growth medium than to cell morphology.

\section{Methods}

Organism. Candida albicans isolate 73/055 was used throughout the experiments. The fungus, originally isolated from a clinical specimen, was maintained on Sabouraud's glucose agar (Oxoid). Inocula were prepared as aqueous cell suspensions from overnight cultures grown on this medium at $37^{\circ} \mathrm{C}$ and washed twice with sterile distilled water. Concentrations of yeast-cells in the inocula were determined by haemocytometer counting, and all media were inoculated with a volume that yielded an initial concentration of $1-5 \times 10^{6}$ cells $\mathrm{ml}^{-1}$. The conditions of inoculum starvation and synchronous reinoculation used by Staebell \& Soll (1985) were not considered pertinent to the present investigation, which was designed to examine envelope expansion parameters in individual cells rather than population characteristics.

Growth media. To obtain cells that developed in a wide diversity of morphological forms, and to avoid selection of effects specific to medium rather than to morphology, eight different culture conditions were used. The media, their $\mathrm{pH}$ and incubation temperatures were: amino acid/salts medium (AAS; Lee et al., 1975, supplemented with $70 \mu \mathrm{g}$ arginine $\left.\mathrm{ml}^{-1}\right) \mathrm{pH} 4.5$ at $37^{\circ} \mathrm{C}$, pH 6.5 at $26^{\circ} \mathrm{C}$ and $37^{\circ} \mathrm{C}$; mycological peptone/glucose broth pH 7.5 (MPGB; Evans et al., $1975 b$ ) at $30^{\circ} \mathrm{C}, 35^{\circ} \mathrm{C}$ and $40^{\circ} \mathrm{C}$; and yeast nitrogen base $/ 1 \%$ glucose broth (YNBG) at $30^{\circ} \mathrm{C}$ and $37^{\circ} \mathrm{C}$.

Microscopic observation of C. albicans. Developing cell evaginations were monitored microscopically within a Sykes-Moore chamber (Bellco Biotechnology). The chamber coverslips were immersed in $0.1 \%$ poly-L-lysine for $1 \mathrm{~min}$, rinsed in water and left in an upright position to dry in air. The coverslips were stored at $4{ }^{\circ} \mathrm{C}$ until required.

C. albicans cell envelopes were marked with polystyrene beads as described by Staebell \& Soll (1985). The beads (polystyrene microspheres, diameter $0.48 \mu \mathrm{m}$; Polysciences, Warrington, PA, USA) were suspended in sterile distilled water then pelleted by centrifugation in a $1.5 \mathrm{ml}$ microtube. To the pellet, $1 \mathrm{ml}$ of $0.1 \%$ poly-L-lysine was added and the suspension was vortexed to disperse the beads. The suspension was then lightly ultrasonicated $(10 \mathrm{~s}$ at $80 \mathrm{~W}$ with a $3 \mathrm{~mm}$ diameter probe), pelleted to remove excess poly-L-lysine, washed twice in sterile distilled water, resuspended in sterile distilled water and again lightly ultrasonicated.

Cultures inoculated with $C$. albicans as described above were incubated for 90-120 min, then 10-40 $\mu$ l of coated bead suspension was added to $1 \mathrm{ml}$ cell suspension. The cells were vortexed, pelleted and resuspended in $1.5 \mathrm{ml}$ of fresh medium prewarmed to incubation temperature. The Sykes-Moore chamber was then inoculated and inverted as described by Soll \& Hermann (1983) so that cells adherent to the poly-L-lysine-coated cover slip could be viewed with a $100 \times$ oilimmersion microscope objective linked to a computer video screen. The temperature in the chamber was kept constant, using a hot air current from an industrial dryer and medium supplied from a reservoir in a thermostatically controlled water bath. Temperature consistency was monitored throughout each experiment either with a surface probe or a thermistor probe inserted in the chamber. Fresh medium was pumped through the chamber by a small peristaltic pump $(0.275 \mathrm{ml}$ $\mathrm{min}^{-1}$ ) which resulted in complete turnover of the chamber medium every $2 \mathrm{~min}$.

Measurement of Mi and zones of cell wall expansion. Cells with one or two polystyrene beads attached to a daughter evagination were selected for monitoring. Measurements were made at $10 \mathrm{~min}$ intervals and were continued for a minimum of $\mathbf{8 0}$ min. Five measurements were made as rapidly as possible at each observation point, since facilities for video recording of the microscopic fields were not available. The measurements were the cell length (apex to base), maximum diameter, diameter at the septal or parent/daughter junction, circumferential distance from this junction to the polystyrene bead $(l)$ and circumferential distance from bead to cell apex $(m)$. The measurements were done by manually tracing the distances on the video image of the microscopic field with the aid of a computerized image analysis system (IMAGAN2; Kompira, Strathclyde, Scotland). From these five measurements, $\mathrm{Mi}$ was calculated according to the formula given by Merson-Davies \& Odds (1989) and the cell semi-perimeter $(n)$ was calculated as the sum of $l+m$.

For analysis of the data, curves of $l$ and $n$ vs time were first plotted for each cell monitored. Since $n$ increased only when a cell was expanding, these curves were inspected first to determine whether the period of active cell expansion ceased during the observation period and thus to determine the duration of the active expansion measured. An experiment was rejected from further analysis when the curve of $l$ or $n$ vs time indicated unacceptable errors in the precision of the measurements or when the period of active expansion monitored was shorter than $60 \mathrm{~min}$.

The values $l_{1}$ and $l_{2}$ i.e. the values of $l$ at the start and end, respectively, of the observation period, and the equivalent values $n_{1}$ and $n_{2}$, were determined by linear regression analysis of curves of $l$ and $n$ vs time. The final $\mathrm{Mi}$ of the cell, $\mathbf{M i}_{\mathrm{f}}$, was determined as the mean of the last three Mi calculations. This statistical approach to determining critical values of $l, n$ and $\mathrm{Mi}$ was chosen to smooth out possible contributions of experimental error in individual data points. The value of $l$ was particularly vulnerable to error in individual measurements, since the distance between the bead and the junction between an evagination and its parent was small initially and usually remained small throughout the expansion period.

The percentage of general envelope expansion was calculated from the formula of Staebell \& Soll (1985), i.e.:

$$
\% \text { General expansion }=100 \times \frac{l_{2}-l_{1}}{\left(\frac{n_{2} \times l_{1}}{n_{1}}\right)-l_{1}}
$$

The rate of expansion of the cell semi-perimeter was calculated in $\mu \mathrm{m}$ $\min ^{-1}$ as the difference between $n_{2}$ and $n_{1}$ divided by the period of observation.

Calculation of data means, standard deviations regression lines and correlation coefficient were done with the aid of Statview software running on an Apple Macintosh computer. 


\section{Results}

Table 1. Parameters of envelope development in $47 \mathrm{C}$. albicans cells monitored in eight growth environments in a Sykes-Moore chamber

\begin{tabular}{|c|c|c|c|c|}
\hline \multirow[b]{2}{*}{ Culture conditions } & \multirow{2}{*}{$\begin{array}{c}\text { No. } \\
\text { tested }\end{array}$} & \multicolumn{2}{|c|}{$\mathbf{M i}_{\mathrm{f}}$} & \multirow{2}{*}{$\begin{array}{c}\text { Mean rate of } \\
n \text { increase } \\
\left(\mu \mathrm{m} \min ^{-1}\right)\end{array}$} \\
\hline & & Range & Mean \pm SD & \\
\hline AAS pH $4.5 / 37^{\circ} \mathrm{C}$ & 4 & $1.0-1.6$ & $1.4 \pm 0.3$ & $0.02 \pm 0.01$ \\
\hline AAS pH $6.5 / 26^{\circ} \mathrm{C}$ & 3 & $1 \cdot 3-1.6$ & $1.4 \pm 0.2$ & $0.03 \pm 0.03$ \\
\hline AAS pH $6.5 / 37^{\circ} \mathrm{C}$ & 7 & $2 \cdot 5-4 \cdot 5$ & $3.6 \pm 0.6$ & $0.16 \pm 0.05$ \\
\hline $\mathrm{MPGB} / 30^{\circ} \mathrm{C}$ & 3 & $1.2-1.9$ & $1.6 \pm 0.4$ & $0.07 \pm 0.04$ \\
\hline $\mathrm{MPGB} / 35^{\circ} \mathrm{C}$ & 9 & $2 \cdot 7-4 \cdot 4$ & $3.7 \pm 0.6$ & $0 \cdot 26 \pm 0 \cdot 10$ \\
\hline $\mathrm{MPGB} / 40^{\circ} \mathrm{C}$ & 2 & $3 \cdot 4-4 \cdot 3$ & $3.9 \pm 0.6$ & $0.16 \pm 0.01$ \\
\hline YNBG $/ 30^{\circ} \mathrm{C}$ & 5 & $1.0-1.6$ & $1 \cdot 3 \pm 0.2$ & $0.02 \pm 0.01$ \\
\hline YNBG $/ 37^{\circ} \mathrm{C}$ & 14 & $2 \cdot 9-4 \cdot 3$ & $3.7 \pm 0.5$ & $0.21 \pm 0.05$ \\
\hline
\end{tabular}

At the completion of experimentation, 20 cells had been monitored in YNBG at $37^{\circ} \mathrm{C}, 10$ in YNBG at $30^{\circ} \mathrm{C}, 11$ in AAS pH 6.5 at $37^{\circ} \mathrm{C}, 9$ in AAS pH 6.5 at $26^{\circ} \mathrm{C}, 10$ in AAS pH 4.5 at $37^{\circ} \mathrm{C}, 5$ in MPGB at $40^{\circ} \mathrm{C}, 13$ in MPGB at $35^{\circ} \mathrm{C}$ and 9 in MPGB at $30^{\circ} \mathrm{C}$. Among the data sets for these 87 cells, 40 were rejected on the basis either of an unacceptable imprecision in the measurements of $l$ or $n$ or too short a period of expansion measurement. The following results are therefore based on an analysis of data for 47 C. albicans cells. The active expansion periods monitored ranged from 60 to $174 \mathrm{~min}$, with observation periods of from 80 to 120 min the most common.

Table 1 summarizes information showing the number of data sets analysed for each set of growth conditions, the $\mathrm{Mi}_{\mathrm{f}}$ in each case, and the mean rate of increase of the cell semi-perimeter, $n$, in each case. Although $\mathbf{M i}_{\mathrm{f}}$ varied between different growth conditions, as was expected and intended, the other parameters gave little evidence of associations with particular media or particular termperatures of incubation. The highest rates of increase in $n$ were seen in AAS pH 6.5 at $37^{\circ} \mathrm{C}$, MPGB at $35^{\circ} \mathrm{C}$ and $40^{\circ} \mathrm{C}$ and YNBG at $37^{\circ} \mathrm{C}$, but these were also conditions that gave the highest mean values of $\mathrm{Mi}_{\mathrm{f}}$. (The association between rate of expansion of $n$ and $\mathrm{Mi}_{\mathrm{f}}$ is examined further below.) Under all conditions of temperature and $\mathrm{pH}$, cell expansion in terms of $n$ was most rapid overall in MPGB (mean of all data for this medium $=0.206 \pm 0.107 \mu \mathrm{m} \mathrm{min}^{-1}$ ) and slowest in AAS (mean of all data $=0.090 \pm 0.077 \mu \mathrm{m} \mathrm{min}^{-1}$ ).

\section{Changes in parameters of envelope expansion with time}

Development of the cells in terms of parameters $n$ (semiperimeter of cell) and $l$ (distance between bead and parent) is illustrated for 3 typical cells with different $\mathbf{M i}_{\mathrm{f}}$ in Fig. $1(a, b)$. It is evident from Fig. 1 that the rate of
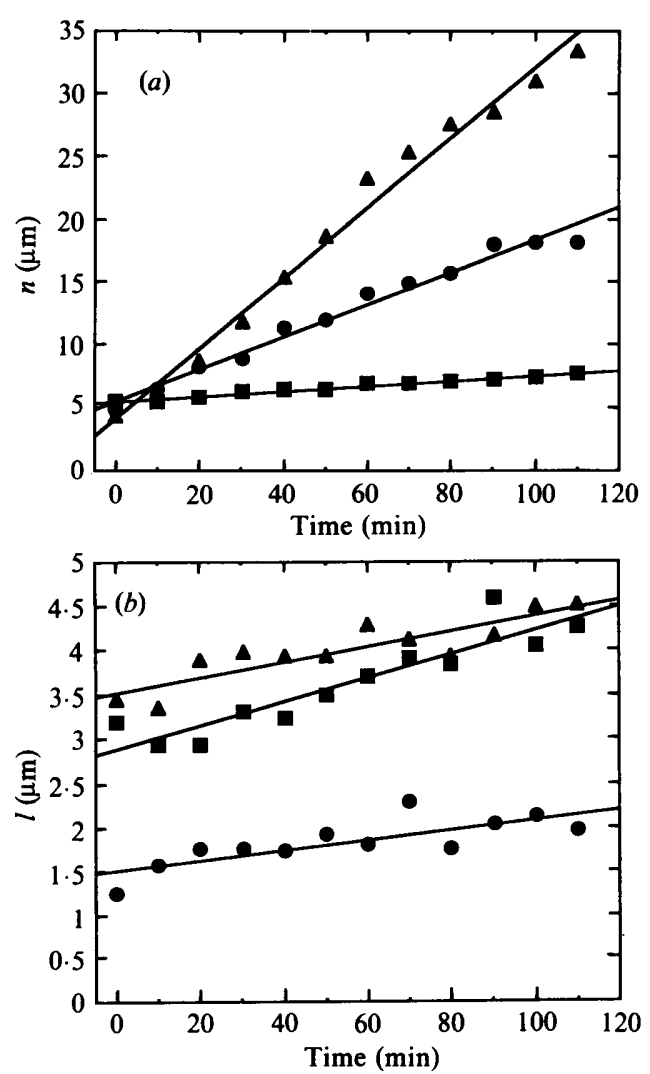

Fig. 1. Examples illustrating (a) expansion of the cell semi-perimeter $(n)$ and $(b)$ the distance between a surface bead marker and the parentdaughter junction $(l)$ for three $C$. albicans $73 / 055$ cells plotted against time., YNBG at $37^{\circ} \mathrm{C}, \mathrm{Mi}_{\mathrm{f}}=2.9 ; \square, \mathrm{YNBG}$ at $30^{\circ} \mathrm{C}, \mathrm{Mi}_{\mathrm{f}}=1.6 ; \Delta$, YNBG at $37^{\circ} \mathrm{C}, \mathrm{Mi}_{\mathrm{f}}=4 \cdot 1$.

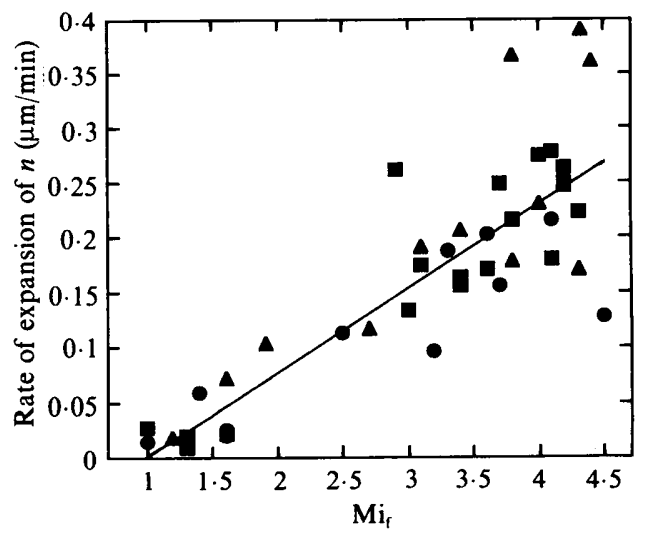

Fig. 2. Rate of expansion of the semi-perimeter $(n)$ for 47 cells of $C$. albicans $73 / 055$, grown in 8 different culture conditions, vs $\mathrm{Mi}_{\mathrm{f}}$. The various symbols indicate points obtained with different culture media: - AAS; $\square$, YNBG; $\triangle$, MPGB. The regression line for expansion rate on $\mathrm{Mi}_{\mathrm{f}}$ is shown $(r=0.87 ; P<0.0001)$.

increase of $n$ was greatest for the cell with highest $\mathrm{Mi}_{\mathrm{f}}$ and lowest for the cell with the smallest $\mathrm{Mi}_{\mathrm{f}}$. Changes in $l$ in the course of 120 min expansion were much smaller than those in $n$. The rate of expansion of the semi-perimeter 


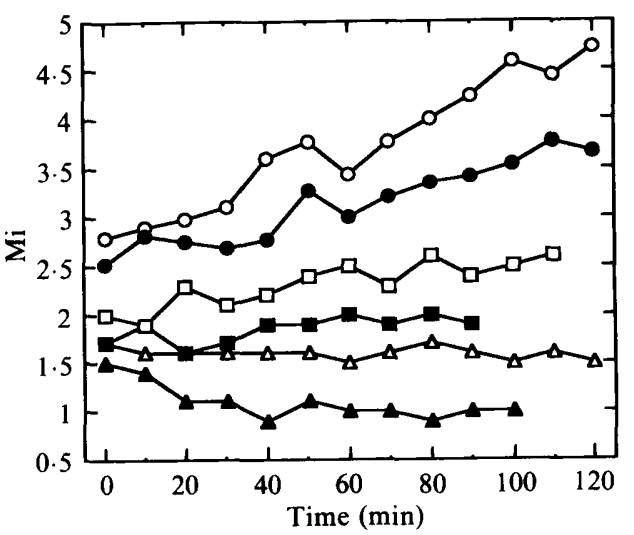

Fig. 3. Development of $\mathrm{Mi}$ with time for 6 representative $C$. albicans cells. $\mathrm{O}, \mathrm{Mi}_{\mathrm{f}}=4.6 ; 0, \mathrm{Mi}_{\mathrm{f}}=3.8 ; \square, \mathrm{Mi}_{\mathrm{f}}=2.4 ; \square, \mathrm{Mi}_{\mathrm{f}}=1.9 ; \triangle$, $\mathrm{Mi}_{\mathrm{f}}=1 \cdot 6 ; \Delta, \mathrm{Mi}_{\mathrm{f}}=1 \cdot 0$.

(n) showed an apparently linear association with $\mathrm{Mi}_{\mathrm{f}}$ (Fig. $2 ; r=0.87 ; p<0.0001$ ). The three different culture media used gave different overall rates of expansion, regardless of differences in incubation temperature (see above) but representative cells over the whole range of $\mathrm{Mi}$ were nevertheless obtained with all three media (Fig. 2).

Among 15 yeast-cells $\left(\mathrm{Mi}_{\mathrm{f}}<2 \cdot 0\right)$, a pattern indicative of the biphasic expansion pattern $A$ described by Staebell \& Soll (1985) was encounted only twice and is therefore not illustrated. The remaining 13 cells with $\mathbf{M i}_{\mathrm{f}}$ below 2.0 showed only a linear increase in $n$ during the observation period and were presumed to be in the secondary (general expansion) phase of development. In all 15 instances, the initial semicircumference at the time of bead attachment was more than $50 \%$ of the final semicircumference, circumstances in which only sicondary expansion would be predicted (Staebell \& Soll, 1985). Analysis of the 2 instances of biphasic growth were therefore done only on the secondary phase of yeastcell expansion.

Mi itself changed with time (Fig. 3). As cells destined towards a high $\mathbf{M i}_{\mathrm{f}}$ developed, their increasingly elongated morphology resulted in an increasing $\mathrm{Mi}$, whereas cells with $\mathrm{Mi}_{\mathrm{f}}<2$ usually retained a more or less constant $\mathrm{Mi}$ value throughout their expansion period. A few cells with $\mathrm{Mi}_{\mathrm{f}}<1.5$ showed a decrease in Mi with time, as illustrated in Fig. 3, indicating a tendency to increasing roundness with continued expansion.

Apical and general components of envelope expansion, and their relation to final $\mathrm{Mi}$

For each of the 47 cell data sets analysed, the proportion of wall expansion that occurred generally throughout the envelope was estimated and plotted against $\mathbf{M i}_{\mathrm{f}}$. The

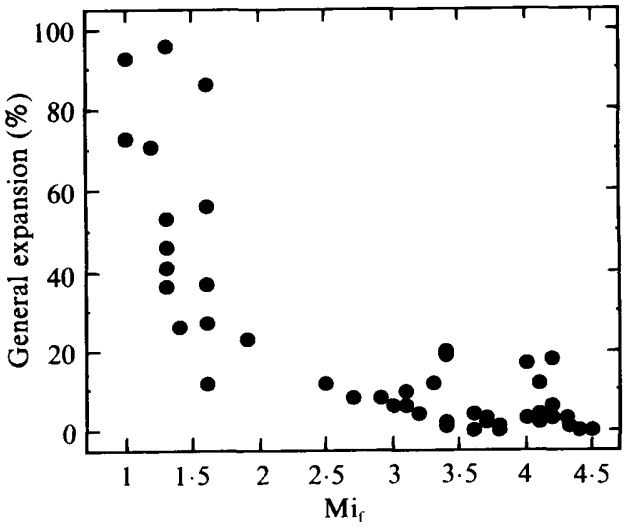

Fig. 4. Percentage of general envelope expansion for 47 cells of $C$. albicans $73 / 055$, grown in 8 different culture conditions, vs $\mathbf{M i}_{\mathrm{f}}$. The data indicate a correlation between the two parameters $(r=0.80$; $P<0.001$ ).

results (Fig. 4) showed that general expansion correlated with $\mathrm{Mi}_{\mathrm{f}}(r=0.80 ; p<0.001)$. However, it can be seen from Fig. 4 that the scatter of points indicates a curved rather than a linear relationship between \% general expansion and $\mathrm{Mi}_{\mathrm{f}}$. It appears that the proportion of general expansion of the cell envelope was considerable only in cells with the lowest $\mathrm{Mi}_{\mathrm{f}}$. General expansion did not exceed $20 \%$ in any of the cells with $\mathrm{Mi}_{\mathrm{f}}>2$ and exceeded $10 \%$ only in a minority of instances. If, in accordance with Staebell \& Soll (1985), apical expansion is assumed to account for the remaining cell envelope expansion, then more than $90 \%$ of wall expansion occurred at the apex for most of the cells with $\mathrm{Mi}_{\mathrm{f}}>2 \cdot 0$.

\section{Discussion}

The essence of the present study was a repetition of the experiments of Staebell \& Soll (1985) but using the objectively measured $\mathrm{Mi}$ of cells grown in a diversity of environments in place of subjective categorization of cell form as either yeast-cells or hyphae. We expected to observe a larger number of cells with intermediate $\mathrm{Mi}$ (in the range 2-3) than was actually found. The reason for this polarization of cells towards extremes of $\mathrm{Mi}$ with fewer mid-range cells is unknown. Anderson et al. (1989) noted a tendency of $C$. albicans opaque cells to grow hyphal forms within Sykes-Moore chambers but not in batch cultures - a phenomenon that parallels the shift towards higher $\mathrm{Mi}$ seen in the present study with conditions that previously gave mainly intermediate forms in batch cultures.

This study confirms the finding of Staebell \& Soll (1985) that extensive generalized surface expansion is a property of yeast-cells and not hyphae, but the relationships found between generalized expansion and $\mathbf{M i}_{\mathrm{f}}$ and 
between expansion rates and $\mathbf{M i}_{\mathrm{f}}$ extend the earlier findings. The design of the present study differed slightly from its forerunner since a different $C$. albicans strain was used and video recordings of developing cells were not used as the basis for measurements, thus reducing the precision of cell measurement. However, our stringent rejection of apparently inadequate data sets and use of statistical analyses to determine critical values of $l$ and $n$ in the present study should have minimized any contribution of imprecisions in individual measurements.

The curve for \% general expansion and $\mathrm{Mi}_{\mathrm{f}}$ (Fig. 4) suggests that apical expansion of the $C$. albicans envelope is predominant through most of the quite different morphologies represented across the range of $\mathrm{Mi}$, with high levels of general envelope expansion encountered only in cells with the lowest $\mathrm{Mi}$. If an $\mathbf{M i}_{\mathrm{f}}$ below 2.0 is assumed broadly to represent yeast-cells, $\mathrm{Mi}_{\mathrm{f}}$ between 2.0 and 3.4, 'pseudohyphae', and $\mathrm{Mi}_{\mathrm{f}}$ above 3.4, true hyphae, then the mean \% general expansion in each category was $52 \pm 27,8 \cdot 3 \pm 2 \cdot 9$ and $5 \cdot 2 \pm 6 \cdot 6$, respectively. Both latter figures are comparable with the $9 \cdot 4 \pm 7.0$ quoted by Staebell \& Soll for hyphal forms. Therefore, generalized expansion of the cell envelope is minimal even for pseudohyphae, where the intermediate shapes have been previously predicted to arise from rates of generalized wall expansion intermediate between those of yeast-cells and hyphae (Odds, 1988).

The finding of a linear association between the rate at which the cell perimeter expands and the final $\mathrm{Mi}$ of the cell (Fig. 2) confirms earlier observations that $C$. albicans hyphae (Davies \& Denning, 1972) and the hyphal cell envelope (Odds, 1985) expand more rapidly than in yeast-cells. From Fig. 2, it can be deduced that the average rate of perimetric extension of the envelope of a cell whose final $\mathrm{Mi}$ is $>3.4$ (a hypha) is more than five times greater than the rate for a cell whose final $\mathrm{Mi}$ is $<1.5$ (a yeast-cell). If the data are recalculated in terms of expansion of surface area on the assumption that cells with $\mathrm{Mi}<1.5$ are spheres and cells with $\mathrm{Mi}>3.4$ are cylinders, the average difference in rate of envelope expansion between yeast-cells and hyphae becomes 10fold. However, these observations are qualified by the fact that the yeast-cells studied here were in their secondary, very slow phase of expansion. During their initial phase of expansion, involving primarily apical synthesis (Staebell \& Soll, 1985), it is possible that yeastcell expansion rates equal those of cells with higher $\mathrm{Mi}$ (these rates were not determined in the earlier publication). The obvious proportionality between final $\mathrm{Mi}$ and expansion rate seen in Fig. 2, even in the Mi range above that of yeast-cells, nevertheless remains intriguing.

In $C$. albicans hyphae, cellular extension is not accompanied by an increase in cytoplasmic content; instead the cytoplasm retains its original mass and migrates behind the expanding apex to leave a highly vacuolated structure distally (Gow \& Gooday, 1982, 1984; Brawner \& Cutler, 1985; Gow et al., 1986). If, in a cell with a high $\mathrm{Mi}$, a rate of envelope expansion much greater than that in a cell with a low Mi must be maintained, it is conceivable that this rate is achieved at the expense of cytoplasmic expansion.

Proportionality between rate of envelope expansion and $\mathrm{Mi}$ is also striking in the context of previous studies showing commitment of $C$. albicans to morphological development. At some point during the evagination of a new cell unit in $C$. albicans, the cell becomes committed to continue development as a yeast or a hypha, so that rapid switching of the growth environment to one that normally favours an alternative cell form has no effect on committed cells (Evans et al., 1975a; Mitchell \& Soll, 1979; Chaffin \& Wheeler, 1981; Soll et al., 1985). However, since it is now evident that the ultimate morphology of a $C$. albicans cell is a point on a continuously variable scale (Mi) rather than one of just two discrete forms (Merson-Davies \& Odds, 1989), the concept of commitment requires reappraisal. It seems teleologically unlikely that a cell can become committed early in its development to a particular final $\mathrm{Mi}$; however, commitment to a particular rate of envelope expansion in response to environment is a credible possibility. Such a model would necessarily indicate that final morphology is somehow determined by rate of envelope expansion.

One postulated mechanism for differential morphology of $C$. albicans cells is based on differences in the rate at which a newly synthesized, visco-elastic wall is subsequently rigidified by cross-linking of wall polymers: high rates of rigidification lead to hyphal forms, low rates to yeast-cells (because their walls are able to expand laterally) and intermediate rates to intermediate forms (Odds, 1979; Shepherd, 1987, 1988, 1990). A wall expansion mechanism based on synthesis of a primary, plastic wall that is later rigidified has now been well demonstrated for apical growth in Schizophyllum commune (Wessels et al., 1983, 1990). Our observation of proportionality between rate of perimeter extension and $\mathrm{Mi}_{\mathrm{f}}$ is compatible with such a model, if it is assumed that rigidification rates parallel, but do not equal, rates of synthesis of primary wall polymers. The rate of secondary rigidification would then be maximal in hyphal cells with high $\mathrm{Mi}_{\mathrm{f}}$ and very slow in cells at the low end of the Mi range wall, allowing yeast-cells the possibility of further primary wall synthesis at all sites in the cell wall, as was seen in cells with low $\mathrm{Mi}_{\mathrm{f}}$ in the present study and in that of Staebell \& Soll (1985). If rigidification depends in molecular terms on cross-linking that involves $\mathrm{N}$ acetyl-D-glucosamine moieties, as seems to be the case 
with other yeasts and fungi (Wessels et al., 1990) then this model is also compatible with the findings of higher chitin levels in the cell walls of $C$. albicans hyphae than in yeast-cells (Chattaway et al., 1968) and the finding that C. albicans chitin levels are directly proportional to $\mathrm{Mi}$ (Merson-Davies \& Odds, 1989).

We are grateful to the Science and Engineering Research Council for a studentship in support of L.A.M.-D. and to David R. Soll and his colleagues for advice on the setting up and use of the Sykes-Moore chambers.

\section{References}

Anderson, J. A., Cundiff, L., Schnars, B., Mingxing, G., MaCKenzIE, I. \& Soll, D. R. (1989). Hypha formation in the whiteopaque transition of Candida albicans. Infection and Immunity 57, 458-467.

Braun, P. C. \& Calderone, R. A. (1978). Chitin synthesis in Candida albicans: comparison of yeast and hyphal forms. Journal of Bacteriology 133, 1472-1477.

Brawner, D. L. \& Cutler, J. E. (1985). Changes in surface topography of Candida albicans during morphogenesis. Sabouraudia Journal of Medical and Veterinary Mycology 23, 389-393.

ChAFFIN, W. L. \& WheELER, D. E. (1981). Morphological commitment in Candida albicans. Canadian Journal of Microbiology 27, 131-137.

Chattaway, F. W., Holmes, M. R. \& Barlow, A. J. E. (1968). Cell wall composition of mycelial and blastospore forms of Candida albicans. Journal of General Microbiology 51, 367-376.

Chattaway, F. W., Shenolikar, S., O'Reilly, J. \& Barlow, A. J. E. (1976). Changes in the cell surface of the dimorphic forms of Candida albicans by treatment with hydrolytic enzymes. Journal of General Microbiology 95, 335-347.

Davies, R. R. \& Denning, T. J. V. (1972). Growth and form in Candida albicans. Sabouraudia 10, 180-188.

Elorza, M. V., Rico, H. \& Sentandreu, R. (1983). Calcofluor white alters the assembly of chitin fibrils in Saccharomyces cerevisiae and Candida albicans cells. Journal of General Microbiology 129, 15771582.

Evans, E. G. V., Odds, F. C. \& Holland, K. T. (1975a). Resistance of the Candida albicans filamentous cycle to environmental change. Sabouraudia 13, 231-238.

Evans, E. G. V., Odds, F. C., Richardson, M. D. \& Holland, K. T. $(1975 b)$. Optimum conditions for initiation of filamentation in Candida albicans. Canadian Journal of Microbiology 21, 338-342.
Gow, N. A. R. \& Gooday, G. W. (1982). Vacuolation, branch production and linear growth of germ tubes of Candida albicans. Journal of General Microbiology 128, 2195-2198.

Gow, N. A. R. \& Gooday, G. W. (1984). A model for the germ tube formation and mycelial growth of Candida albicans. Sabouraudia 22, 137-143.

Gow, N. A. R., Henderson, G. \& Gooday, G. W. (1986). Cytological interrelationships between the cell cycle and duplication cycle of Candida albicans. Microbios 47, 97-105.

Lee, K. I., Buckley, H. R. \& CAMpbell, C. C. (1975). An amino acid liquid synthetic medium for the development of mycelial and yeast forms of Candida albicans. Sabouraudia 13, 148-153.

Merson-Davies, L. A. \& OdDs, F. C. (1989). A morphology index for characterization of cell shape in Candida albicans. Journal of General Microbiology 135, 3143-3152.

MitChell, L. H. \& Soll, D. R. (1979). Commitment to germ tube or bud formation during release from stationary phase in Candida albicans. Experimental Cell Research 120, 167-179.

ODDs, F. C. (1979). Morphogenesis in Candida, with special reference to C. albicans. In Candida and Candidosis, pp. 29-41. Leicester: Leicester University Press.

ODDs, F. C. (1985). Morphogenesis in Candida albicans. CRC Critical Reviews in Microbiology 12, 45-93.

ODDs, F. C. (1988). Morphogenesis in Candida, with special reference to C. albicans. In Candida and Candidosis, 2nd Edn, pp. 42-59. London: Bailliere Tindall.

SHEPHERD, M. G. (1987). Cell envelope of Candida albicans. CRC Critical Reviews in Microbiology 15, 7-25.

SHEPHERD, M. G. (1988). Morphogenetic transformation of fungi. Current Topics in Medical Mycology 2, 278-304.

ShePHERD, M. G. (1990). Biology of Candida species. In Oral Candidosis, pp. 10-20. Edited by L. P. Samaranayake and T. W. MacFarlane. London: Wright.

Soll, D. R. \& HeRMANN, M. A. (1983). Growth and the inducibility of mycelium formation in Candida albicans: a single-cell analysis using a perfusion chamber. Journal of General Microbiology 129, 28092824.

Soll, D. R., Hermann, M. A. \& Staebell, M. A. (1985). The involvement of cell wall expansion in the two modes of mycelium formation of Candida albicans. Journal of General Microbiology 131, 2367-2375.

StaEbell, M. \& Soll, D. R. (1985). Temporal and spatial differences in cell wall expansion during bud and mycelium formation in Candida albicans. Journal of General Microbiology 131, 1467-1480.

Wessels, J. G. H., Sietsma, J. H. \& SonNenberg, A. S. M. (1983). Wall synthesis and assembly during hyphal morphogenesis in Schizophyllum commune. Journal of General Microbiology 129, 1607-1616.

Wessels, J. G. H., Mol, P. C., Sietsma, J. H. \& Vermeulen, C. A. (1990). Wall structure, wall growth, and fungal cell morphogenesis. In Biochemistry of Cell Walls and Membranes in fungi, pp. 81-95. Edited by P. J. Kuhn, A. P. J. Trinci, M. J. Jung, M. W. Goosey \& L. G. Copping. Berlin: Springer-Verlag. 